\title{
Milena Petrović*
}

University of Arts in Belgrade,

Faculty of Music,

Solfegio and Music Education Department

\section{Gordana Ačić**}

Music school "Dr. Vojislav Vučković" in Belgrade

\section{Vera Milankovic $* * *$}

University of Arts in Belgrade,

Faculty of Music,

Solfegio and Music Education Department

\section{SOUND OF PICTURE VS PICTURE OF SOUND: MUSICAL PALINDROME}

\begin{abstract}
This study investigated whether and how the musical palindrome (tonal, melodic and metric) can be recognized in auditory and/or visual perception in musically trained participants. According to the results, we suggest that palindrome recognition can only be aurally perceived if it is short enough and the listener is quite sophisticated. There is a fair amount of research on the recognition of transformed auditory and visual patterns, as well as the visual symmetry perception in persons with ASD. Thus, a future study will test more people with $\mathrm{ASD}$, on one hand, and musically trained participants recognizing short musical palindromes.

Key words: musical palindrome, mirror symmetry, musically trained participants, auditory and visual symmetry, melodic symmetry, tonal context, meter, dynamics, staccato, ASD
\end{abstract}

* Author contact information: pepa.magare@gmail.com

** Author contact information: gordanaacic@gmail.com

*** Author contact information: vera.milankovic@gmail.com 


\section{Symmetry}

During the early $20^{\text {th }}$ century, the Gestalt school of psychology argued that people perceive objects more in organized groups/formations (Koffka 1935). There are some general rules which can apply to all the human senses (Peeples 2010, Rosenblum 2010). Principles such as similarity and proximity rather precede symmetry in visual (Labonté et al. 2002), but not in auditory perception (Shepard, Levitin 2002). The important role of symmetry perception in the visual domain has been well documented in a large number of studies, but its effect is less clear as a Gestalt grouping principle in the audio domain.

Humans prefer ordered, symmetrical over random patterns (Kayne 1994). In humans, transition symmetry, rotational symmetry and mirror symmetry is mainly perceived as repeats, rotations and reflections (Wagemans 1997). The socalled mirror symmetry (palindrome) represents the mirror reflection of a microor macro-formal structure around a vertical or a horizontal axis simultaneously or successively (Drivas, 2009). It is the most experimentally examined type of symmetry and it is considered the most important and easiest to recognize for humans (Beck et al. 2005). As a fundamental Gestalt principle, symmetry is the characteristic of many different biological shapes, for example, Y chromozomes are structured of symmetrical (palindromic) sequences. Some researchers claim that mirror symmetry is an innate ability (Pinker, 1997) and that at 4 months infants are able to distinguish it around the vertical axis (Rhodes et al. 2002). The fMRI imaging in humans confirmed the superiority of mirror symmetry perception around a vertical axis (Rollenhagen, Olson 2000). Symmetry is very important for memory because symmetrical objects have a better mnemonic encoding, recognition and recall (Stucchi et al. 2010). For recognition of symmetry humans engage only short-term memory (Hogben, Julesz, Ross 1976). Symmetry is the major determining factor in aesthetic judgments and the aesthetic preference for it may be related to the easier and more effective processing of our cognitive-perceptual system for objects classified as symmetric (Reber, Schwarz, Wienkielman 2004). Hence, symmetry is fundamental for understanding art because it is an example of a possible convergence in visual and auditory perception (Redies, Hasenstein, Denzler 2007).

\section{Mirror-symmetry palindrome in music}

In music, the retrograde motion/mirror-symmetry palindrome represents a unique compositional technique which means that the music is the same when played forwards or backwards. In counterpoint, the retrograde motion should happen directly without a break (Newbould 2001/2002). Reflection in music has 
Petrović, M., Ačić, G., Milanković, V., Sound of Picture vs Picture of Sound...

the effect of "running time in reverse" and transforming the sequence of events in a piece of music accordingly. Despite having been in use in music practice for centuries, the retrograde canon and palindrome principle represent a less investigated field of compositional technique (Božanić 2015: 316). Some authors have thought of the palindrome as: the philosophy of the absurd, a logical paradox, a tendency for mathematical abstraction, the magic of numbers, the aesthetics of the game, etc. (Božanić 2015: 318). In the $14^{\text {th }}$ century, the first composed palindrome was Machault's polyphonic Rondo. Bach's 'crab canon' from the $\mathrm{Mu}$ sical Offering is a famous palindrome where the composer wrote a note to the performer saying "by seeking you will find". Bach's son Carl Philipp Emanuel Bach wrote a full-textured palindrome as his Minuet in C Major. It is not surprising that Haydn probably heard C.P.E. Bach's palindrome Minuet and then composed his famous Menuet al reverso as the third movement of his Symphony No.47. The only example of a music palindrome in the whole $19^{\text {th }}$ century music was Schubert's Die Zauberharfe of 1820 (Newbould 1992). Schubert considered the palindrome as a demonic symbol but also as the product of intellectual manipulation. In the $20^{\text {th }}$ century, there have been many examples such as Berg's Lulu, Weber's $2^{\text {nd }}$ movement from the Piano Variations op. 27 and Stockhausen's Mixtur.

\section{Music/melodic symmetry perception}

Symmetry, as a specific aspect of repetition, represents one of the universal principles in music. But, the perception of auditory symmetry received little scientific attention. It can manifest itself in a temporal series of loudness levels, frequencies, timbres, sound source locations, or in a series of frequencies heard simultaneously (Mongoven, Carbon 2016). Some authors consider melodic symmetry cannot be a universal perceptual grouping principle because it is hard to detect (Mongoven and Carbon 2016). Symmetry can be realized in musical structure and form, compositional systems and styles (Kempf 1996). Several studies concentrated on the perception of melodic symmetry. In 1972, Frances found listeners perceived the retrograde inversion of the given sequences in the absence of melodic, rhythmic, and harmonic variations, probably because they may have obscured the perceived relationship between the prime form and its mirror transformation. That same year of 1972, two other studies (Dowling and DeLannoy) showed listeners were not able to identify mirror forms (retrograde, inversion, and retrograde inversion transformations) of atonal sequences that consisted of equal duration. However, listeners were able to detect the temporal reorganization of tones in a 12-tone series in a single octave, probably because 
of the changes in the melodic contour (Pedersen 1975). Balch's (1981) results show that listeners better perceived the inversion and retrograde form of the first part of melodies, but concluded melodic symmetry must be perceptible in order to enhance the aesthetic value of a diatonic melody. Castellano et al. (1984) pointed out that listeners familiar with Western music can set aside their tonal knowledge and perceive the hierarchies appropriate to a novel musical style. The findings of Krumhansl and others (1987) in four experiments show that: 1) the classification accuracy of mirror forms (inversion, retrograde and retrograde inversion) of the 12-tone row is higher for the neutral sequences (musically neutral materials) than the musical excerpts (Schoenberg's Wind Quintet and String Quartet, No. 4);2) some listeners can perceive the similarity between the original form and its three mirror forms despite mirror transformation, the octave transposition of tones and variations of rhythm and phrasing; 3) the perception of various mirror forms is better if they are short; 4) perception correlates with musical training. It is probable that musical training plays a significant role in the perception of melodic symmetry because in a later study (Mongoven and Carbon 2016), the participant who scored the highest in accuracy was a doctoral student in music composition, while the participant with the lowest accuracy had no musical training. The authors suggested that difficulty in recognition and categorization of mirror forms correlates with an extremely fast tempo, short duration and long tones (Mongoven and Carbon 2016). But, broken symmetry and its small or strong violation arises from the fact that mathematical and musical logic are not necessarily compatible (Kempf 1996).

In our study, we tested musically trained participants because symmetry perception correlates with musical training (Krumhansl 1987, Mongoven and Carbon 2016). We chose classical music, early medieval music and traditional folk music, knowing symmetry does exist in different styles (Kempf 1996). Like retrograde symmetry perception is higher for the musically neutral materials of atonal music (Krumhansl et al. 1987), we believed the case would be the opposite for modal and tonal music. We chose all three palindromes according to their aesthetic values that are important in perceiving symmetry (Balch 1981). Better perception of retrograde forms of tonal melodies (Balch 1981, Castellano et al. 1984) persuaded us to use Haydn's Minuet and folk song palindromes. Although the auditory/visual symmetry perception had previously been applied for tonal (Balch 1981, Castellano et al. 1984) and atonal music (Dowling 1972, DeLannoy 1972, Pedersen 1975, Krumhansl et al. 1987) we tested whether modality increased or decreased the ability for auditory and/or visual symmetry perception. The absence of rhythm in the medieval sequence palindrome probably would help listeners perceive the retrograde of the given sequence (France 
Petrović, M., Ačić, G., Milanković, V., Sound of Picture vs Picture of Sound...

1972). We used a very short Serbian folk song to check whether perception of the mirror forms was better if they were short (Krumhansl et al. 1987) or if the short duration created difficulties in music symmetry recognition (Mongoven and Carbon 2016).

\section{Method}

The aim was to show whether and how a music palindrome (tonal, melodic, metric) can be recognized in auditory and/or visual perception in musically trained students - specifically to detect the palindrome as a sound or image.

The subjects participated in the study on a voluntary basis. They were not told the aim of the study in order to free their attention and relax them. The 100 bachelor and master students at the Faculty of Music, University of Arts Belgrade were divided into two groups: 50 students in the Music Education Department (first-year 6, second-year 15, third-year 18, fourth-year 8 , master degree 3 ) and 50 students in the different instrumental departments (piano 20, flute 7 , oboe 5, clarinet 3, bassoon 2, trumpet 2, horn 1, jazz 10). Each participant had at least 10 years of formal music education in instrumental/vocal music in Serbian music schools.

\section{Part I}

I) Listening and notating:

a) Haydn's Menuet

b) Short medieval palindrome

c) Serbian folk song "Oh, girl, where did you pluck a rose?"

II) Completing questionnaire:

1. How would you describe the music you just heard?

2. Does this music remind you of some other music?

3. Did you memorize the melody?

4. Are you able to sing it?

5. Did some of the parameters present a problem while listening?

6 . Did some of the parameters help you out?

7. Did the duration affect your auditory perception?

8. Did you listen/notate the music as a whole or in parts?

9. Did the form recognition make listening easier?

10. Circle the chronological schedule of listening parameters (tempo, form, meter, rhythm, melody, articulation, dynamics) 
Part II:

I) Singing a prima vista three palindromes in the same order

II) Completing questionnaire:

1. How would you describe the music you just sang?

2. Does this music remind you of some other music?

3. Does this music provoke music associations?

4. Do you remember the melody you just sang?

5 . Did some of the parameters present a problem while singing?

6. Did some parameters help you out?

7. Did the duration affect your visual perception?

8. Did you sing the music as a whole or in parts?

9. Did the recognition of the form make singing easier?

10. Circle the chronological schedule of listening parameters (tempo, form, meter, rhythm, melody, articulation, dynamics)

\section{Apparatus}

The stimulus materials in Part I were three musical excerpts performed in the original context. Haydn's Minuet was performed by Tafelmusic in 1993 with Bruno Weil as the conductor. The Minuet was played on the YouTube channel at a comfortable listening level. The laptop HP Compaq $6715 \mathrm{~b}$ was used and positioned in front of the listeners. The medieval sequence and the Serbian folk song were sung by the examiner (Milena Petrović). In Part II, separate music sheets were used for all three palindromes.

\section{Stimulus materials}

Haydn's palindrome has the $\mathrm{AB}$ form with a 10-bar structure in each part. The $B$ part is the mirror symmetry palindrome as the melody, rhythm, dynamics and articulation are the same as in the A part, although in reverse. As such, metric accents are the only ones that mismatch, but they are replaced with strong dynamic accents. 
Petrović, M., Ačić, G., Milanković, V., Sound of Picture vs Picture of Sound...

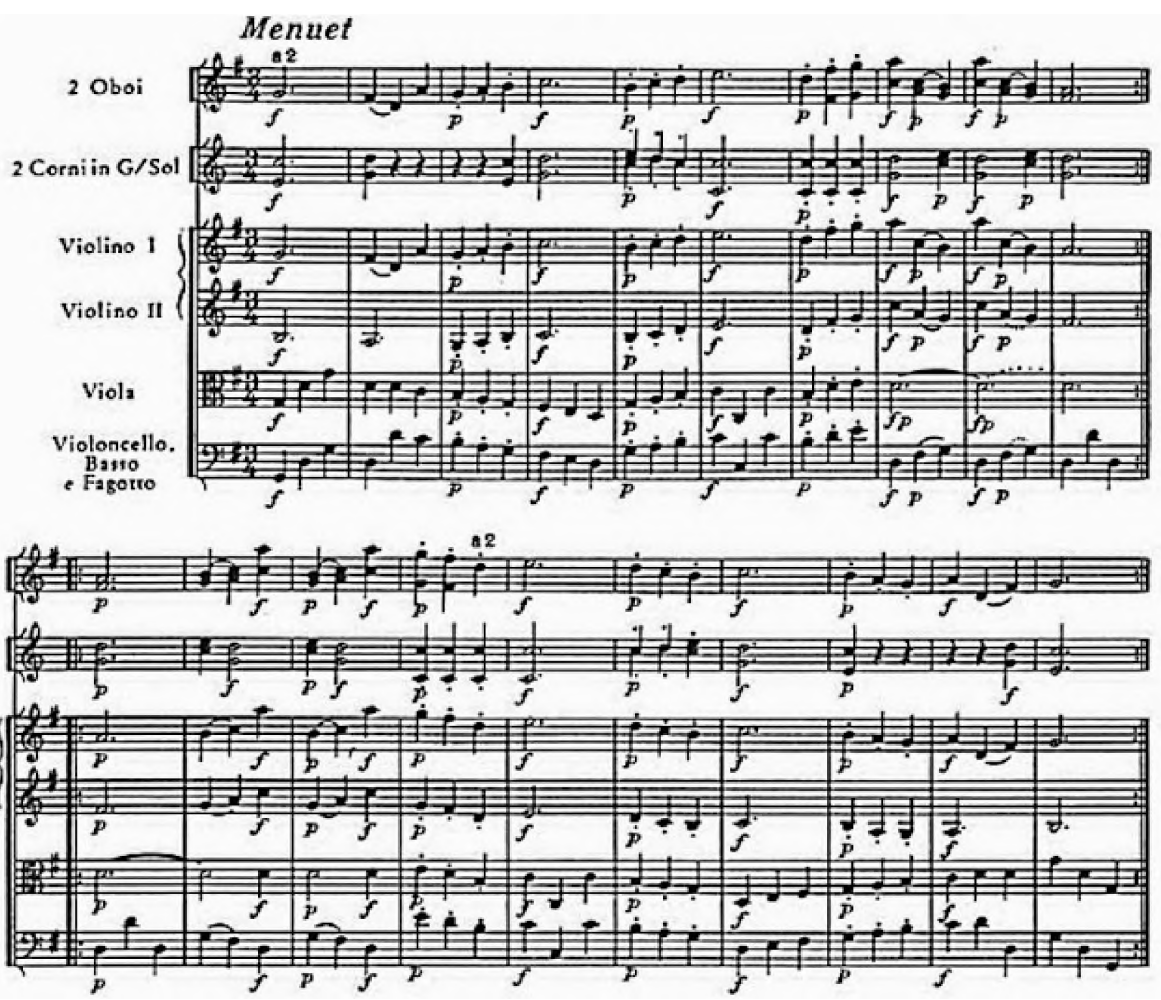

Example 1: Haydn's Minuet from Symphony No. 47, third movement

The palindrome in the medieval style of Guido d'Arezzo Hymn "Ut queant laxis" consists of the modal 27-tone melody without rhythm and meter. It was composed for research purposes. The lyrics are taken from the Gregorian chant "Maria veri solis mater libera". The melody is syllabic - one pitch in the melody goes with one syllable in the words. The axis of symmetry appears on the $14^{\text {th }}$ tone $\mathrm{G}$ after which the melody goes in reverse.

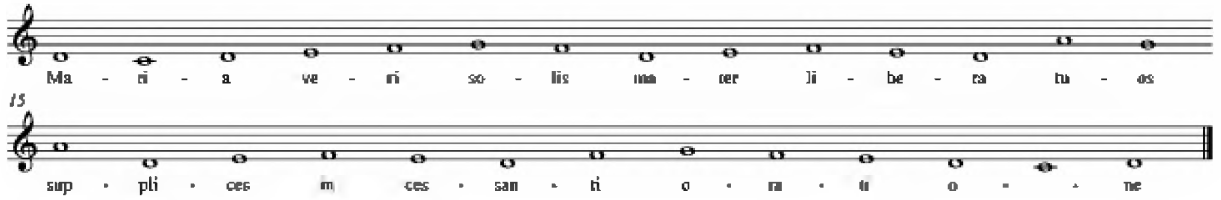

Example 2: Medieval modal sequence composed for research purposes

A very short, 6-bar Serbian folk song "Oh, girl, where did you pluck a rose" contains a metrical palindrome, as the metrical pattern $3 / 4-5 / 8-2 / 4$ is the same 
when the music goes forward and in reverse (b. 4-6). The real tonal context is made just with the first three steps of the minor scale.

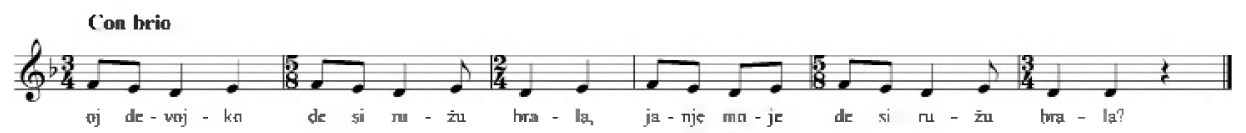

Example 3: The Serbian folk song "Oh, girl, where did you pluck a rose?"

\section{Procedure}

Our study was conveyed during regular solfeggio classes. Participants were given precise instructions for the two-part experiment where Part II was conducted two weeks after Part $I$.

Part I consisted of listening and notating music in groups (up to 15 participants per group) in the following order: a) Haydn's Minuet 4 times the whole +4 times the A part +4 times the B part +4 times the whole + questionnaire; b) Medieval sequence 12 times the whole + questionnaire; c) Serbian folk song 12 times the whole + questionnaire. Between listening to repetitions there was a break of 10 seconds. After each palindrome there was a 30 -second break. The time needed to complete each questionnaire was 10 minutes. Part I lasted about 60 minutes.

Part II consisted of individual singing a prima vista of the same three palindromes in the same order. Participants had two minutes of preparation time for each palindrome, respectively. After singing, they completed the questionnaire.

\section{Results}

Part I showed only three students aurally recognized Haydn's Minuet as a palindrome. They were: 1) a first-year student in the Wind Dept. (oboe); 2) a thirdyear student in the Music Education Dept.; 3) a fourth-year student with ASD in the Music Education Dept. All three students started their music education before the age of eight and within their families there were musically educated members. From their questionnaire we read that the salient dynamic accents and staccato articulation helped them recognize the mirror transformation of the first part of Haydn's Minuet.

Part II showed that all the participants did not recognize the musical palindromes visually.

The role of the questionnaires was to investigate whether somebody recognized the palindrome and to explain how. Reading the questionnaires, we re- 
Petrović, M., Ačić, G., Milanković, V., Sound of Picture vs Picture of Sound...

alized that participants listen and perform music as a whole that helps them in perception and recognition.

\section{Discussion}

We chose musically trained participants because we believed auditory and visual symmetry perception is 1) correlated with music training; 2) higher for the musical excerpts than for the neutral sequences (musically neutral materials); 3) easier if the materials are in a tonal manner. Three students did recognize only Haydn's palindrome aurally probably because of the tonal context. Our results coincided with the results concerning tonal context from the previous studies (Balch 1981, Castellano et al. 1984). Students are used to tonality because it is the foundation on which Serbian music education rests. Reading questionnaires we understand that more than tonality it was the immediate repetitions of the dynamics and staccato accents that helped the students recognize Haydn's palindrome. Dynamics and articulation seem archetypical and important in helping to group music structure (Benett 1992: 12). In this study we did not take into account tempo, but it is very possible that a moderately fast tempo influenced the participants' symmetry recognition in Haydn's Minuet.

We chose the same palindromes to test visual symmetry perception in a two-week period for those participants who did not recognize them aurally. The participants who did recognize Haydn's Minuet aurally were excluded from Part II. Interestingly enough, only a few participants recognized that the same music pieces were used for the Part II experiment, but all the other participants failed to recognize the music palindromes visually. It is indicative that students of the Jazz Department did not recognize the music palindromes especially because symmetry plays an important role with musical notions of form, melody, harmony and rhythm in jazz music (Uriarte 2016).

We reached the conclusion that melodic and metric symmetry is hard to recognize both aurally and visually. Probably the difficulties in recognition are caused by the absence of meter (in the medieval sequence) on the one hand, and the metrical complexity (in the folk song) on the other. Beside meter, the medieval sequence did not have a rhythm, which could have helped students perceive the retrograde sequence (Frances 1972). But, as nobody recognized the medieval palindrome, we believe that the absence of meter, modality, Latin lyrics and long equal-tones made symmetry perception more difficult (Mongoven and Carbon 2016). Although shortness makes the perception of mirror forms easier (Krumhansl et al. 1987) the Serbian folk song metric palindrome might have been difficult to recognize due to the change in the isochronous and non-isochronous meter. The Serbian lyrics were an additionally aggravating factor in the recognition of the metric palindrome. 
In the group of participants who aurally recognized Haydn's palindrome was a student with ASD. Probably, this result correlates with the recent study (Carper et al. 2016) showing more symmetry across the right and left hemispheres in children and adolescents with ASD (41) than within the matched group of typically developing TD (44). This can be the reason why people with autism show skill in identifying specific details in music and processing global information. Further, symmetry seems to be a domain of difference between visual patterns and music or language (Westphal-Fitch et al. 2012) and children with ASD appear to fixate from an early age on audio-visual synchrony and have better discrimination of pitch and symmetry (Klin et al. 2009). Regarding visual symmetry, the ordering of objects in symmetrical patterns is notably frequent among young children diagnosed with ASD (Evans et al. 1997). Hence, they are able to quickly determine whether a complex pattern is visually symmetrical or not (Falter 2012). But, we did not see the result concerning recognition of the visual palindrome in music as a success. Despite participants with ASD (17) being significantly more sensitive to visual symmetry than TD (15) (Perreault et al. 2011), our results show the Gestalt grouping was selectively impaired in terms of visual organization principles.

\section{Conclusion}

In this study, the musical palindrome was perceived through sound that implicated auditory symmetry perception. We are inclined to think that music as a frozen image cannot prompt visual symmetry perception and therefore our participants did not recognize musical palindromes visually. The melodic contour did not help in recognizing the musical palindrome visually, so no correlation between the musical contour and palindrome symmetry perception was found (Dowling 1972).

The question is whether the palindrome requires focusing on grouping or detecting details. On the one hand, there were musically trained participants who listened and performed the music as a whole (according to their questionnaires). On the other hand, people with ASD have the ability to isolate details within a global context (according to the relevant literature). Most likely, symmetry perception presents a spatially global process (Hogben et al. 1976). Therefore, musically trained participants (3) recognized Haydn's palindrome probably because of its tonal context and dynamics and articulation (as details) that help grouping symmetrical stimuli in music. 
Petrović, M., Ačić, G., Milanković, V., Sound of Picture vs Picture of Sound...

\section{Works cited}

Beck, D.M. et al.: "Symmetry perception in humans and macaques", Trends in Cognitive Sciences. No. 9, 2005, 405-406.

Benett, G.: "The Sense of the Phrase - Compositional Grouping in Music", in: J. Sundberg (Ed.), Gluing Tones Grouping in Music Composition, Performance and Listening.

Stockholm: Royal Swedish Academy of Music and the authors, 1993, 9-27.

Božanić, Z.: Teorija složenog kontrapunkta na primeru muzičke prakse strogog stila, doktorska disertacija. Beograd: Fakultet muzičke umetnosti, 2015.

Carper et al.: "Reduced Hemispheric Asymmetry of White Matter Microstructure in Autism Spectrum Disorder", Journal of the American Academy of Child and Adolescent Psychiatry. Vol. 55, Issue 12, 2016, 1073-1080.

Darwin, C: The Descent of Man. London: John Murray, 1871.

Drivas, V.: "Symmetry and the plain", available

http://nicomedia.math.upatras.gr/ oxy/symmetry/symmetry_chap3.pdf.

Evans, J. F. et al.: "Ritual, habit, and perfectionism: the prevalence and development of compulsive-like behavior in normal young children", Child Development. No. 68, 1997, $58-68$.

Falter, C.M.: "Impaired and superior mirror symmetry perception in autism", Autism. No. 17(1), 2012, 117-118.

Hogben, J. H. et al.: "Short-term memory for symmetry", Vision Research. No. 16, 1976, 861-866.

Kayne, R. S.: The antisymmetry of syntax. Cambridge, MA: MT Press, 1994.

Kempf, D.: "What is Symmetry in Music?", International Review of the Aesthetics and Sociology of Music, Vol. 27, No. 2, 1996, 155-165.

Klin et al.: "Two-year-olds with autism orient to non-social contingencies rather than biological motion", Nature. No. 459, 2009, 257-261.

Koffka, K.: Principles of Gestalt Psychology. New York: Harcourt Brace, 1935.

Kolpakov, R., Kucherov, G.: "On maximal repetitions in words", Journal of Discrete Algorithms, No. 1(1), 2000, 159-186.

Leone, G. et al.: "Independence of bilateral symmetry detection from a gravitational reference frame", in: C. W. Tyler (Ed.), Human symmetry perception and its computational analysis. Mahwah, NJ: Lawrence Erlbaum Associates, 2002, 111-121.

Mongoven, Carbon: "Acoustic Gestalt: On the Perceptibility of Melodic Symmetry", Musicae Scientiae, 2016, 1-19.

Newbould, B.: "A Schubert Palindrome", 19th_Century Music, Vol. 15, No. 3, 1992, 207214.

Newbould, B., "Palindrome", in: Stanley Sadie (Ed.), The New Grove Dictionary of Music and Musicians. London: Macmillian Publishers, 2001-2002, 2-3.

Peoples, L.: "Making scents of sounds", Scientific American, No. 302 (4), 2010, 28-29.

Perreault, A. et al.: "Increased sensitivity to mirror symmetry in autism", PLoS One, No. 6(4), 2011, https://doi.org/10.1371/journal.pone.0019519

Reber, R. et al.: "Processing fluency and aesthetic pleasure: Is beauty in the perceiver's processing experience?", Personality and Social Psychology Review, No. 8, 2004, 364. 
Redies, C. et al.: "Fractal-like image statistics in visual art: Similarity to natural scenes", Spatial Vision, No. 21, 2007, 137-148.

Rhodes, G., Zebrowitz, L. A.: Advances in visual cognition (Vol. 1). Facial attractiveness: Evolutionary, cognitive and social perspectives. Westport, CT: Ablex, 2002.

Stucchi, N. et al.: "The perceptual salience of symmetrical and asymmetrical sections of a line", Perception, No. 39, 2010, 1026-1042.

Tinio, P.L., Leder, H.: "Just how stable are stable aesthetic features? Symmetry, complexity, and the jaws of massive familiarization", Acta Psychologica, No. 130, 2009, 241150 .

Uriarte, G. S.: Symmetry in the music of Thelonious Monk and Steve Coleman. Master Thesis, New Jersey: Faculty of William Paterson University of New Jersey, 2016.

Wagemans, J.: "Characteristics and models of human symmetry detection", Trends in Cognitive Science, No. 1(9), 1997, 346-352.

Westphal-Fitch, G.W., Huber, L.: "Production and perception rules underlying visual patterns: Effects of symmetry and hierarchy", Philosophical Transactions of the Royal Society B Biological Sviences, No. 367, 2012, 2007-2022.

\section{Summary}

The main aim of the research was to test whether musically trained participants are able to perceive auditory and/or visual mirror symmetry (palindrome) in music. The sample of 100 participants (50 students in the Music Education Dept. and 50 students in the Performing Dept.) listened and notated musical palindromes in groups, and two weeks after individually sang a prima vista the same three musical palindromes. We took three types of palindrome: 1) tonal (Haydn's Minuet), 2) melodic (medieval modal sequence) and 3) metrical (a Serbian folk song). Three participants, one of them diagnosed with autism spectrum disorder (ASD) did recognize only Haydn's palindrome auditory, but none of them recognized palindromes visually. Most likely, tonal context has a decisive role in symmetry music perception. In Haydn's palindrome, dynamics accents and staccato, probably caused palindrome auditory recognition. With the second palindrome we found that musically trained participants were not able to recognize the melodic palindrome most likely because this equal-tone modal melody does not have a meter. Finally, metrical complexity in the form of isochronous and non-isochronous metric change within the third palindrome probably reduced the possibility of recognizing a metric palindrome. We assume lyrics were an additionally aggravating factor in the recognition of both the melodic and the metric palindrome, while the moderately fast tempo in Minuet additionally helped grouping and, consequently, auditory symmetry recognition. 